\title{
A framework for funding culturally appropriate recovery for people affected by severe mental illness: a world view
}

\author{
Robert Parker
}

\begin{abstract}
Summary
Mental illness is becoming a significant factor in disability throughout the world. In recent years, The concept of Recovery has become an important component of what is considered to be a benchmark of the treatment outcome for those affected by severe mental illness. However, the concept is complex because of the range of factors that impact on successful Recovery and the economic means of enabling these factors. Economic strategies to
\end{abstract}

address significant disadvantage of Indigenous peoples in Australia and Canada, based on ideals of health developed by the World Health Organisation along with recent economic thinking to empower agency for change in disadvantaged people may lead to a similar strategy to develop Recovery programs in different economic and cultural systems.

SL J Psychiatry 2011; 2 (2):45-48

\section{Introduction}

Mental illness is a significant factor in disease related disability throughout the world. About $16 \%$ of the global burden of disease not attributable to communicable disease has been attributed to mental disorders (1). People suffering from severe mental illness currently face significant levels of poor health, high levels of unemployment, homelessness, alienation from family members and services (2-6). The economic cost of these issues to society generally is significant with people affected by schizophrenia estimated to have provided a direct cost to the United States economy of $\$ 62.7$ billion in 2002 (7).

\section{Recovery from mental illness}

As a way of approaching the widespread issues of disability related to the experience of severe mental illness and developing hope, the Recovery Movement has gaining increased currency in recent years. Leff \& Warner note that " the model refers both to the subjective experiences of hope, healing, empowerment and interpersonal support experienced by people with mental illness, their carers and service providers and to the creation of recovery-oriented services that engender a positive culture of healing and a support for human rights" (8). The authors add that, as a result of the Recovery movement, there is renewed interest in fighting the stigma that leads people with mental illness to lose their sense of self, to provide access to the services and education that give mental health clients the knowledge and skills to manage their illness, empowering consumers to share responsibility with providers in the healing process and providing access to peer support that validates the possibility of recovery (8).

Unfortunately, the economic basis of supporting effective Recovery does not appear to have matched the theoretical process of empowerment and particularly so in the developed world. The observation that people suffering from schizophrenia often have a better outcome from disease in the third world may be related to the situation where economic opportunity (such as having meaningful work on a family farm or in a family kitchen) along with a place to sleep and adequate diet may be much easier to provide within the economic restraints and social supports of third world countries (9). Warner has also commented on the nature of work in less developed countries that may be protective for someone suffering from severe mental illness. He notes that the person's family is less likely to emotionally smother the individual and the tasks allocated to the individual are likely to be geared to the level of performance that the person can actually achieve (9). In comparison, the costs of providing adequate housing and meaningful employment to individuals in developed countries are often significantly higher. In addition, it often has been difficult for governments to provide coordinated sustained funding for such programs across a range of different government departments that have responsibility for each program. The difficult task of addressing the above issues in the developed world is exemplified in a recent evaluation of the cost of mental illness in Canada in 2003. The review found that the cost of undiagnosed mental illness was about $28 \%$ of a total cost of $\$ 50,847$ million dollars with direct medical costs of treating mental illness contributing only about $10 \%$ of this amount with the remainder being attributed to lost productivity (10).

\section{World definitions of health}

The issue of Recovery in Mental Illness also has to be viewed in the context of recent world developments to define an appropriate policy approach to health along with innovative theoretical approaches to empowerment of impoverished individuals. One could argue that one of the more potent expressions of economic and social poverty is exemplified by individuals affected by severe mental illness. The World Health Organisation Declaration of Alma-Ata (1978) defined health as "a state of complete physical, mental and social wellbeing and not merely as the absence of disease and infirmity" as a fundamental human right. The Declaration further called on all governments to formulate national policies, strategies and plans of action to launch and sustain primary health care as part of a comprehensive national health system and in co-ordination with other sectors". 
The Ottawa Charter for Health Promotion (1986) built on the initial foundations of the Declaration of AlmaAta. The Charter reported that health "is therefore seen as a resource for everyday life, not the objective for living" and "as a positive concept emphasizing social and personal resources as well as physical capacities". The Charter goes on to define the prerequisites for health as: "peace, shelter, education, food, income, a stable eco-system, sustainable resources, social justice and equity".

\section{Amartya Sen and the concept of Empowerment of Human Agency}

Apart from above broad based definitions of health, there has also been an appreciation of economic opportunities associated with the empowerment of human agency, ideas further developed by Amartya Sen, who was awarded the Nobel Prize for Economic Science in 1998. Sen defines "agency" as "someone who acts and brings about change and whose achievements can be judged in terms of their own values and objectives, whether or not we assess them in terms of some external criteria as well" (11). Sen then goes on to discuss the way that instrumental effectiveness of freedom may enhance this potential for agency. "This instrumental role of freedom concerns the way different kinds of rights, opportunities and entitlements contribute to the expansion of human freedom in general and thus to promoting development". Sen then defines his instrumental freedoms as (1) political freedoms (civil rights), (2) economic freedoms (the opportunities to utilize economic resources for the purposes of consumption, production and exchange), (3) social opportunities (arrangements for education, health care etc), (4) transparency guarantees (transparency and trust in personal interaction) and (5) protective security (unemployment benefits, famine relief etc). These instrumental issues then underpin substantive freedoms for humanity such as political and civil liberty, social inclusion, literacy and economic security. The work of Sen is having as significant impact on individuals concerned with enhancing the agency of deprived groups such as those people affected by severe mental illness and this will be further discussed later in the chapter. Henry further defines the issues that Sen promotes "Sen also notes that a second subset of other relevant capabilities of considerable interest to the classical economists - such as the capability to live without shame, the capability to participate in the activities of the community, and the capability of enjoying self-respect - provides a basis for relative poverty comparisons....policy makers should be concerned with opportunities (12). Specifically, they should be concerned to ensure that individuals are endowed with capabilities that allow them the freedom to choose to live their lives in ways that have real meaning and real value....".

\section{Economic strategies to address indigenous disadvantage}

In recent years, there has been a substantive economic effort to address the broad issues of profound disadvantage experienced by the Indigenous populations of Canada and Australia using the above World Health Organisation Principles in addition to the economic empowerment of human agency as described by Sen. Kirmayer has described the significant destruction of
First Nations culture and society in Canada following European contact (13). This has resulted in profound health disadvantage for Canadian First Nations people (14). In the early part of the twenty first century, the Canadian government, in association with First Nations Leaders developed the Canadian Aboriginal Horizontal Framework as a strategic guide to funding priorities and co-operation between the various levels of government as well as allowing the establishment of performance indicators (15). The Framework appears to place the "pillars" of health at equal value. The "pillars" were: Health, Lifelong Learning, Safe and Sustainable Communities, Housing, Economic Opportunity, Lands and resources and Governance and Relationships. The Framework had $\$ 8.2$ billion allocated. Unfortunately, it was dissolved after the election of a Conservative Canadian government in 2006.

In Australia, Aboriginal and Torres Strait Islander peoples have experienced similar significant disadvantage after European colonization in 1788 (16). In 2008, Ken Henry, the Secretary of the Australian Treasury led an economic initiative developed through the Council of Australian Governments to redress Indigenous disadvantage. The proposal by Henry, based on the concepts of enhancement of human agency espoused by Sen, resulted in the formation of the Council of Australian Governments National Indigenous Reform Agreement (12). The building blocks of the strategic financial agreement between the Australian Federal and State Governments were based on the primary care principles outlined in the Ottawa Charter. The Building Blocks outlined by the Agreement are: Early Childhood (early learning, development and socialization opportunities), Schooling (infrastructure, workforce, curriculum, student literacy and numeracy achievement. and opportunities for parental engagement and school/community partnerships), Health (access to effective, comprehensive primary and preventative health care), Economic Participation ( real jobs, business opportunities, economic independence and wealth creation), Healthy Homes (adequate water and sewerage systems, waste collection electricity and housing infrastructure), Safe Communities (improved, accessible law and justice responses, effective policing. "safe houses", child protection and alcohol policy) and Governance and Leadership (capacity building so that Indigenous Australians can play a greater role in exercising their rights and responsibilities as citizens) (17). The Agreement also had specific funding of $\$ 4.6$ Billion tied to the "Building Blocks" to allow their progression by the Australian Commonwealth and State governments.

\section{Ways forward for enhancing recovery}

So if one was to consider a similar economic strategy to those previously discussed with the aim of effectively funding Recovery in Mental illness, what might the pillars be? I have expanded at length on this topic in a recent publication and what follows is a summary (18).

1. Physical Health services to address the 17 year gap in life expectancy for those affected by severe mental illness. There have been a number of effective primary care models developed in Australia and overseas to remedy this issue. 
2. Social Inclusion, addressing issues such as reduction of stigma and meaningful work

3. Education has been found to be an important component in health empowerment, both for affected individuals and those who care for them. Education programs may include enhanced knowledge of mental illness and it's management through school curricula and mental health literacy programs for adults in addition to mental health education for services such as the police as well as focused education for affected individuals and their families

4. Effective Treatments There is a benefit to costing effective treatments in mental illness and comparing these costs against the substantive amounts associated with inpatient admission. Evidence based interventions that have been found to be beneficial for people suffering from mental illness are collaborative psychopharmacology, assertive community treatment, family psycho education, supported employment, illness management and recovery skills and integrated dual diagnosis treatment (19).

5. Substance Abuse. Alcohol, cannabis and amphetamine abuse have been demonstrated to have continuing destructive effects on the mental health of individuals and their families. No funding strategy to address the mental health of a nation can be considered to be effective without addressing these issues.

6. Response to Disaster and Trauma Informed Care. The exposure of populations to disaster has been demonstrated to have significant ongoing influences on the mental health of the affected population. In addition, there has been recent recognition of such issues such as Intergenerational trauma and how this has significant destructive effects on communities.

7. Housing is an important concept for developing mental health. Recent reviews have focused on concepts such "ontological security" (constancy, daily routines, privacy and a secure base for identity construction) that are provided by stable housing and enhance mental health.

8. Governance generally encompasses issues such as safety of patients and staff, the focus on clients and their families, including formal participation in the management and clinical services of mental health organisations. Other governance issues include a skilled and valued workforce, using critical incidents as learning opportunities, continuous improvement of clinical care, and structures of accountability that need to be recognised in any budgetary process for mental health.

Adopting or considering such a strategy for mental health Recovery may enable a way forward in what is often considered a complex and often overwhelming area. It is also a strategy that can be adapted to the economic and cultural needs and requirements of various governments that may wish to develop such a reform program.

\author{
Declaration of interest \\ None
}

\section{Robert Parker}

Adjunct Professor of Psychiatry, James Cook University and Northern Territory Clinical School, Australia

E mail: Robert.Parker@nt.gov.au

\section{References}

1. Prince M, Patel V, Shekhar S, Maselka J, Phillips MR \& Rahman A No health without mental health Lancet; 2007; 370; 859-877 CrossRef

2. Symonds D \& Parker R The Top End Mental Health Services General Practice Clinic: an initiative for patients with serious mental illness. Australasian Psychiatry 2007; 15 (1): 58-61 CrossRef

3. Dunn E, Wewiorski N \& Rogers ES The Meaning and Importance of Employment to people in Recovery from Serious Mental illness: Results of a Qualitative Study; Psychiatry Rehabilitation Journal 2008; 32(1); 59-62 CrossRef

4. Browne $G$ \& Hemsley $M$ Consumer participation in housing: reflecting on consumer preferences. Australasian Psychiatry 2010; 18(6) 579-583 CrossRef

5. Druss BG, Hwang I, Petuhova M, Sampson NA, Wang PS \& Kessler RC Impairment in role functioning in mental and chronic medical disorders in the United States: results from the National Comorbidity Survey Replication. Molecular Psychiatry; 2008; 14; 728-737 CrossRef

6. Luhrmann T "The Street Will Drive You Crazy"; Why Homeless Psychotic Women in the Institutional Circuit in the United States Often Say No to Offers of Help. American Journal of Psychiatry; 2008; 165; 15-20 CrossRef

7. Wu EQ, Birnbaum HG, Shi L, Ball DE, Kessler RC, Moulis $M$ \& Aggarwal $J$ The Economic Burden of Schizophrenia in the United states in 2002. Journal of Clinical Psychiatry; 2005; 66; 1122-1129 CrossRef

8. Leff J \& Warner R Social Inclusion of People with Mental illness. 2006; Cambridge University Press. Cambridge UK http://dx.doi.org/10.1017/CBO9780511543937

9. Warner R Recovery from schizophrenia in the Third World. Psychiatry; 1983 46; 197-212

10. Lim K-L, Jacobs P, Ohinmaa A, Schopflacher D \& Dewa CS A new population-based measure of the economic burden of mental illness in Canada; Chronic Diseases in Canada; 200828 (3) 92-98 PMid:18341763

11. Sen A Development as Freedom. Oxford University Press. 1999 Oxford

12. Henry $\mathrm{K}$ Addressing Extreme Disadvantage through Investment in Capability Development. Closing Keynote Address to the Australian Institute of Health and Welfare Conference "Australia's Welfare 2007" 2007 www. treasury.gov.au/documents/1327/PDF/Health_and_ Welfare_Conference.pdf - (accessed March 2008)

13. Kirmayer L, Brass G \& Tait C The Mental Health of Aboriginal Peoples: Transformations of Identity and Community. Canadian Journal of Psychiatry, 2000; 45, pp607-616 PMid:11056823 
14. MacMillan H, MacMillan A, Offord D \& Dingle J Aboriginal health. Canadian Medical Association Journal. 1996; 155(11), pp 1569-1578 PMid:8956834 PMCid:1334995

15. Canadian Aboriginal Horizontal Framework (2005) http://dsp-psd.pwgsc.gc.ca/Collection/BT1-10-20051E.pdf (accessed Nov 2011)

16. Parker R. Australia's Aboriginal Population and Mental Health. The Journal of Nervous and Mental Disease. 2010; 198 (1): 3-7 CrossRef

17. COAG (2008) Council of Australian Governments National Partnership Agreement on Indigenous Economic Participation http://www.coag.gov.au/ intergov_agreements/federal_financial_relations/ docs/national_partnership/national_partnership_on indigenous_economic_participation.pdf (Accessed December 2011)

18. Parker R A New Economic and Social Paradigm for Funding Mental Health in the Twenty First Century 2011 http://www.intechopen.com/articles/show/title/a-neweconomic-and-social-paradigm-for-funding-recoveryin-mental-health-in-the-twenty-first-century (Accessed December 2011)

19. Mueser K, Torrey W, Lynde D, Singer P \& Drake R Implementing Evidence-Based Practices for people with Severe Mental Illness; Behaviour Modification 2003; 27 (3) $387-411$ CrossRef 